\title{
In vitro mechanism of action for the cytotoxicity elicited by the combination of epigallocatechin gallate and raloxifene in MDA-MB-231 cells
}

\author{
EMMA C. STUART ${ }^{1}$, REAGAN M. JARVIS ${ }^{2}$ and RHONDA J. ROSENGREN ${ }^{1}$ \\ Departments of ${ }^{1}$ Pharmacology and Toxicology, ${ }^{2}$ Biochemistry, University of Otago, Dunedin, New Zealand
}

Received April 12,2010; Accepted May 28, 2010

DOI: 10.3892/or_00000921

\begin{abstract}
The anticancer effects elicited by epigallocatechin gallate (EGCG) are well established in various models of cancer, while raloxifene is as an established selective estrogen receptor modulator (SERM), which is not yet clinically utilized for the treatment of breast cancer. Previous study from this laboratory has demonstrated that the combination of EGCG $(25 \mu \mathrm{M})$ and raloxifene $(4 \mu \mathrm{M})$ elicits a strong cytotoxic response in MDA-MB-231 human breast cancer cells, which lack the estrogen receptor (ER) and erbB-2/ Her-2 receptor. This study was therefore designed to probe the mechanism underlying this cytotoxic response, with an emphasis on determining how the combination treatment influenced the total expression and phosphorylation of key signaling proteins. Specifically, following 12 and $18 \mathrm{~h}$ of the combination treatment, we observed significant decreases in the phosphorylation of the epidermal growth factor receptor (EGFR), AKT, mammalian target of rapamycin (mTOR) and S-6-kinase (S6K), and significant increases in the phosphorylation of stress activated protein kinases (SAPKs). Furthermore, these changes were associated with a reduction in the nuclear localization of $\mathrm{p} 65$, a major subunit of NF- $\mathrm{KB}$. These results demonstrate that the combination of EGCG and raloxifene effectively reduced the mitogenic and survival signaling in MDA-MB-231 cells. Thus, this combination warrants further experimentation as a potential treatment for ER-negative breast cancer.
\end{abstract}

\section{Introduction}

Breast cancers have traditionally been categorized according to the estrogen receptor (ER) status of the tumor (1-4). However, in more recent years it has become evident that as a disease breast cancer is heterogeneous beyond this traditional

Correspondence to: Dr Rhonda J. Rosengren, Department of Pharmacology and Toxicology, 18 Frederick Street, Adams Building, University of Otago, Dunedin, New Zealand

E-mail: rhonda.rosengren@otago.ac.nz

Key words: epigallocatechin gallate, raloxifene, MDA-MB-231 cells classification method. Therefore, several groups have generated more descriptive classifications, based on tissue microarray analyses of breast tumors (5-9). As this method of classification relies on a global assessment of mRNA expression, and involves the use of hierarchical gene clustering, more clearly defined subgroups of breast cancers have been described from these initial tumor sets. Specifically, four major groups were outlined, and include the ER-positive, luminal A and luminal B classifications, the ER/Her-2 classifications and the basal-like classification, which lacks the expression of ER $\alpha$ and Her-2 (5-9). The current breast cancer therapeutics utilized in the clinic, tamoxifen and herceptin, are targeted toward the ER and erbB2/Her-2 proteins, respectively (10-12). Accordingly, both of these drugs rely upon the tumor expression of the aforementioned proteins in order to be efficacious (13). While a significant proportion of breast cancers express either one or other of these proteins, the basal-like subset of breast cancers express neither (5-9). Therefore, these tumors are intrinsically refractory to current drug therapies employed for the successful treatment of breast cancers.

One option for treating these cancers may be to utilize existing breast cancer drugs in combination with other compounds. Currently, tamoxifen, a selective estrogen receptor modulator (SERM) is utilized in the clinic for the treatment of ER $\alpha+$ tumors and for the prevention of breast cancers in high-risk individuals. Recently the Study of Tamoxifen and Raloxifene (STAR) trial determined that raloxifene, a newer generation SERM, was as efficacious as tamoxifen for the prevention of ER-positive breast cancer (14), while the Multiple Outcomes of Raloxifene Evaluation (MORE) trial demonstrated that raloxifene was a highly efficacious drug for the treatment of invasive ER-positive breast cancers (15). Importantly, raloxifene therapy was not associated with adverse uterine effects, which are observed with tamoxifen treatment $(14,15)$. Therefore, raloxifene represents a viable treatment option for breast cancer.

Our laboratory has previously demonstrated that the combination of raloxifene and EGCG is particularly cytotoxic toward the aggressive, basal-like (ER-negative/HER-2negative) MDA-MB-231 cell line (16). Specifically, we have shown that the combination of EGCG and raloxifene elicited a strong apoptotic response, which occurred independently of cell cycle changes (16). Therefore, the aim of the current study was to further investigate whether this treatment regime 
elicited changes in the phosphorylation status of various cell signaling proteins in order to further determine the therapeutic potential of this drug combination.

\section{Materials and methods}

Chemicals. MDA-MB-231 and MCF-7 cells were purchased from ATCC (Manassas, VA). Epigallocatechin gallate (EGCG), 99\% purity, was purchased from Cayman Chemical (Ann Arbor, MI). Fetal bovine serum and trypsin were purchased from Life Technologies (Auckland, New Zealand). Complete protease inhibitor cocktail tablets were purchased from Roche (Mannheim, Germany). Dimethyl sulfoxide was purchased from BDH chemicals (Poole, England). Biotinylated alkaline phosphatase, nitrocellulose, N'-N'-bis-methyleneacrylamide (bisacrylamide), precision plus kaleidoscope SDS-PAGE molecular weight standards, sodium dodecyl sulfate and streptavidin were purchased from Bio-Rad (Hercules, CA). Mouse polyclonal antibodies for EGFR, pEGFR, AKT, JNK1/2, pJNK1/2 and mouse monoclonal antibodies for pAKT, P38 and pP38 were purchaced from BD Biosciences (San Jose, CA). Rabbit polyclonal antibodies for S6K, pS6K, mTOR and actin and mouse monoclonal antibodies for $\beta$-Raf, ER $\alpha$ and ER $\beta$ were purchased from Abcam (Redfern, Australia).

Cell maintenance. MDA-MB-231 and MCF-7 cells were maintained in Modified Eagle's Medium- $\alpha$ modification media (MEM) (pH 7.4) supplemented with $10 \%$ FBS, $1 \%$ antibiotic/antimycotic solution and $0.2 \% \mathrm{NaHCO}_{3}$. Cells were cultured in $75 \mathrm{~cm}^{2}$ flasks and incubated in $5 \% \mathrm{CO}_{2} / 95 \%$ humidified air at $37^{\circ} \mathrm{C}$. Confluent flasks of MDA-MB-231 cells were passaged at two day intervals, while MCF-7 cells were passaged at three day intervals in order to maintain the cells in an exponential growth phase. Both cell lines were passaged a maximum of 15 times, after which reconstituted frozen stocks of MDA-MB-231 or MCF-7 cells were utilized.

Whole cell lysate preparation. MDA-MB-231 or MCF-7 cells were plated in $100 \mathrm{~mm}$ culture dishes at a density of $2 \times 10^{6}$ cells per dish, in $20 \mathrm{ml}$ of DMEM media supplemented with $10 \%$ FBS, $1 \%$ antibiotic/antimycotic solution and $0.2 \% \mathrm{NaHCO}_{3}$. Cells were treated with EGCG $(25 \mu \mathrm{M})$ raloxifene $(4 \mu \mathrm{M})$, EGCG + raloxifene or DMSO $(0.1 \%)$ for $0-18 \mathrm{~h}$. Cell lysates were prepared as previously described (16). Protein concentration was determined using the BCA assay (17) and the samples were stored at $-80^{\circ} \mathrm{C}$ for a maximum of 6 months.

Nuclear and cytosolic fraction preparation. MDA-MB-231 cells were seeded as described for whole cell lysate preparation, and all procedures were carried out at $4^{\circ} \mathrm{C}$. At the end of each treatment, media were removed, and $4 \mathrm{ml}$ of ice cold buffer A $(10 \mathrm{mM}$ Hepes, $10 \mathrm{mM} \mathrm{KCl}, 0.1 \mathrm{mM}$ EDTA, $0.1 \mathrm{mM}$ EGTA, pH 7.8) was added, and cells were detached using a cell scraper, transferred to a fresh tube, and dishes washed with buffer A. Cells were pelleted and resuspended in $0.2 \mathrm{ml}$ of fresh buffer A with the addition of $1 \mathrm{mM}$ DTT and $1 \mathrm{mM}$ PMSF. Cells were transferred to a $1.6 \mathrm{ml}$ microfuge tubes, and $4.8 \mu \mathrm{l}$ of $25 \% \mathrm{NP}-40$ was added to each tube, after which tubes were centrifuged at $10,000 \mathrm{x}$ g for $1 \mathrm{~min}$ at $4^{\circ} \mathrm{C}$ and the pellet was washed in $0.1 \mathrm{ml}$ of buffer A with the addition of $1 \mathrm{mM}$ DTT, $1 \mathrm{mM}$ and $2.4 \mu \mathrm{l}$ of $25 \% \mathrm{NP}-40$. Cells were vortexed and centrifuged again at $10,000 \mathrm{x}$ g for $1 \mathrm{~min}$ at $4^{\circ} \mathrm{C}$. The supernatant (cytosolic sample) was removed to fresh tubes and placed on ice, and the pellet was resuspended in $110 \mu \mathrm{l}$ of buffer B (20 mM Hepes, $0.4 \mathrm{M} \mathrm{NaCl}, 1 \mathrm{mM}$ EDTA, $1 \mathrm{mM}$ EGTA, $1 \mathrm{mM}$ DTT, $1 \mathrm{mM}$ PMSF; pH 7.9). Tubes were then mixed continuously for $45 \mathrm{~min}$ at $4^{\circ} \mathrm{C}$, after which tubes were then centrifuged for at $10,000 \mathrm{xg}$ for $10 \mathrm{~min}$ at $4^{\circ} \mathrm{C}$, and the supernatant (nuclear sample) was collected, aliquoted and snap frozen. All procedures were carried out at $4^{\circ} \mathrm{C}$. Protein concentration was determined using the BCA assay (17) and the samples were stored at $-80^{\circ} \mathrm{C}$ for a maximum of 6 months.

Western immunoblotting. Discontinuous polyacrylamide gels were used to separate $15 \mu \mathrm{g}$ of protein lysates, as previously described (16) using a Bio-Rad Mini-Protean III apparatus. Proteins were transferred to a nitrocellulose membrane using a Bio-Rad Semidry Transblotter, after which membranes were blocked in 5\% non-fat milk powder, and exposed to primary antibodies overnight, then secondary and tertiary antibodies, before visualization using the alkaline phosphatase detection system. Bands were analyzed by densitometry with a Bio-Rad GS-710 Calibrated Imaging Densitometer and analyzed using Image Quant ${ }^{\mathrm{TM}}$ TL software (Amersham).

Statistical analyses. For data that did not involve time, statistical analyses were undertaken using a one-way analysis of variance (ANOVA) coupled with Bonferroni post-hoc test. For data that did involve time, statistical analyses were undertaken using a two-way ANOVA coupled with a Bonferroni post-hoc test. For both types of analyses, $p<0.05$ was the minimum requirement for a statistically significant difference.

\section{Results}

Effect of combination treatment on intracellular signaling proteins. As we had previously observed changes in the phosphorylation of EGFR and AKT signaling proteins in MDA-MB-231 cells following combination treatment with EGCG and raloxifene (16), we decided to perform a more comprehensive investigation into the effect of this treatment on intracellular signaling proteins. Here, we investigated the expression of EGFR and AKT expression and phosphorylation over a time-course. We further explored downstream signaling targets of these proteins, including mTOR, S6K, ERK1/2 as well as the SAPKs, JNK1/2 and p38 (Fig. 1). pEGFR levels were significantly reduced by EGCG + raloxifene versus all other treatments following 6,12 and $18 \mathrm{~h}(82.6 \pm 4.6 \%$, $78.7 \pm 1.9 \%$ and $78.4 \pm 4.1 \%$ of control, respectively, $\mathrm{p}<0.05)$ (Fig. 2A). Next we investigated the expression and phosphorylation of AKT at Ser473, where pAKT was significantly reduced by the combination treatment after 6,12 and $18 \mathrm{~h}$ $(91.9 \pm 2.1 \%, 83.2 \pm 2.0 \%$ and $68.9 \pm 2.3 \%$ of control, respectively, p<0.05) (Fig. 2B). Next, we investigated mTOR expression and phosphorylation, where the combination treatment significantly reduced the levels of pmTOR compared to all other treatments following 6,12 and $18 \mathrm{~h}$ $(64.5 \pm 6.2 \%, 38.7 \pm 4.7 \%$ and $59.3 \pm 4.5 \%$ of control, respectively, p<0.05) (Fig. 2C). S6K is a downstream target of $\mathrm{mTOR}$, therefore we investigated the total expression and 


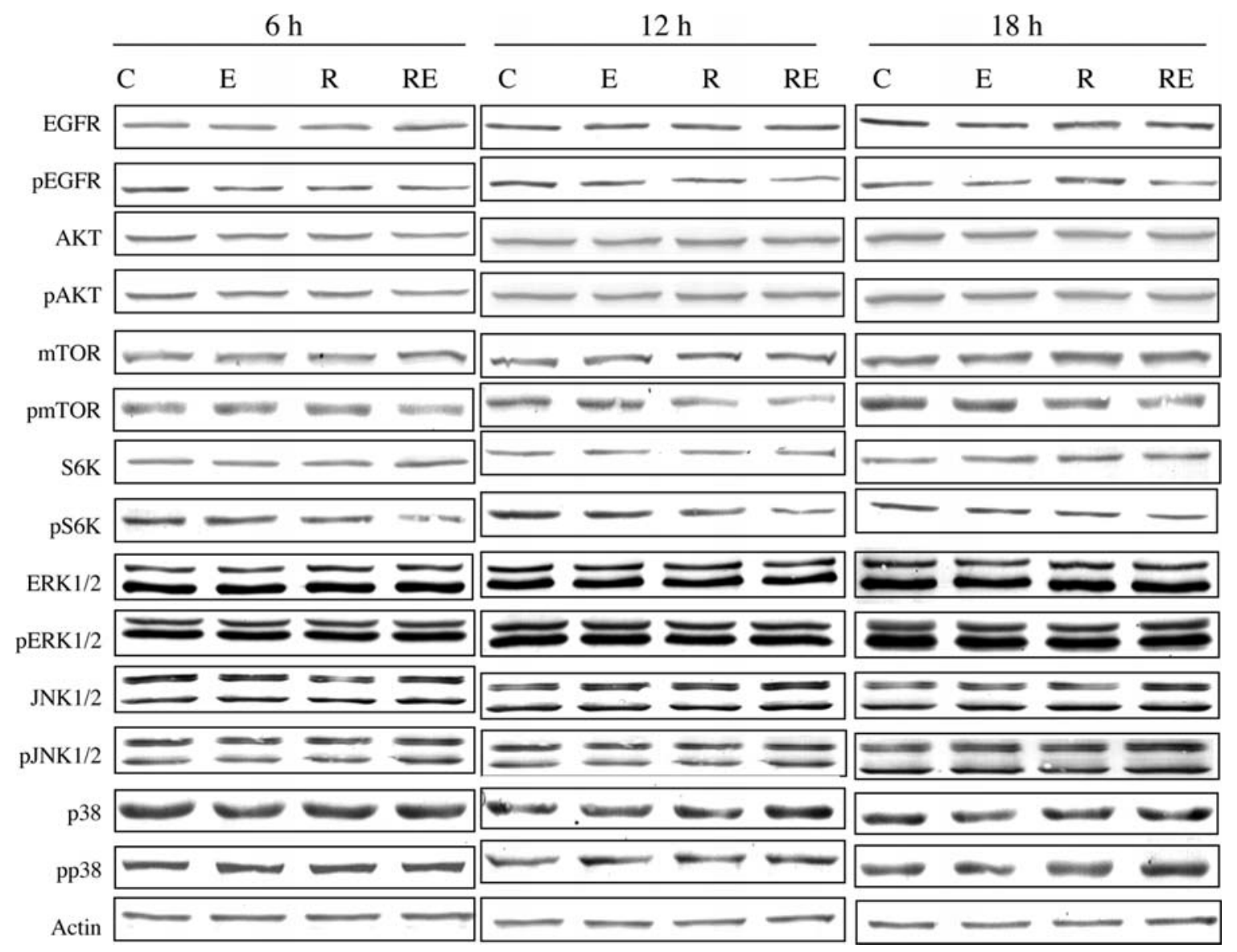

Figure 1. Protein expression of intracellular signaling proteins following treatment with EGCG + raloxifene. Cells were treated with either EGCG $(25 \mu \mathrm{M})$, raloxifene $(4 \mu \mathrm{M})$ or a combination of the two for 6,12 or $18 \mathrm{~h}$. Representative Western blots of total protein expression and protein phosphorylation of EGFR, AKT, mTOR, S6K, ERK1/2, JNK1/2 and p38. C, control; E, EGCG; R, raloxifene; RE, EGCG + raloxifene.

phosphorylation of S6K, where, with the exception of the $12 \mathrm{~h}$ time point, which was only significant against the control and EGCG $(57.7 \pm 9.5$ of control, $\mathrm{p}<0.05)$, the combination treatment significantly reduced S6K phosphorylation versus all other treatment groups $(39.9 \pm 7.2 \%$ and $53.9 \pm 8.6 \%$ of control after 6 and $18 \mathrm{~h}$, respectively, p<0.05) (Fig. 2D). EGCG + raloxifene did not significantly alter the total expression of $\mathrm{p} 38$, however $18 \mathrm{~h}$ of combination treatment significantly increased p38 expression versus all other treatments $(114.9 \pm 4.2 \%$ of control, respectively, $\mathrm{p}<0.05)$ (Fig. 2E). Similarly, the only significant increase in p38 phosphorylation occurred following 12 and 18 of combination treatment, where this was significant versus all other treatment groups $(119.8 \pm 16.1$ and $143.7 \pm 11.8 \%$ of control, respectively, $\mathrm{p}<0.05$ ) (Fig. $2 \mathrm{~F})$. The combination treatment also increased JNK $1 / 2$ expression after $18 \mathrm{~h}$ versus control (126.1 $\pm 12.3 \%$ of control, respectively, p<0.05) (Fig. 2G), and increased the phosphorylation of JNK1/2 after 12 and $18 \mathrm{~h}$ of treatment, where this was significant compared to all other treatments $(132.0 \pm 8.8 \%$ and $153.6 \pm 16.4 \%$ of control, respectively, $\mathrm{p}<0.05)$ (Fig. $2 \mathrm{H}$ ).

Confirmation of a viable EGFR and a lack of ER response in MDA-MB-231 cells. To demonstrate that the MDA-MB-231 cells exhibit a viable EGFR response, cells were serum starved for $24 \mathrm{~h}$ and treated with $100 \mathrm{ng} / \mathrm{ml}$ of EGF for 5, 10, 15 and
$30 \mathrm{~min}$, after which cell lysates were prepared and subjected to Western blotting. A clear kinetic response was observed with the phosphorylation of the EGFR, AKT, ERK1/2 and S6K, indicating the downstream activity of EGFR stimulation in the MDA-MB-231 cells (Fig. 3A). Furthermore, to illustrate that raloxifene cannot be acting as an ER $\alpha$ antagonist, MDAMB-231 cells and MCF-7 cells were treated with ethynlestradiol $(100 \mathrm{nM})$ or EGCG $(100 \mu \mathrm{M})$ and the protein expression of ER $\alpha$ and ERß was then determined by Western blotting. The results showed that our MDA-MB-231 cells do not express ER $\alpha$ protein and that EGCG $(100 \mu \mathrm{M})$ did not restore ER $\alpha$ expression (Fig. 3B). Thus there was no ER $\alpha$ for raloxifene to antagonize following combination treatment and the effects elicited by the combination of raloxifene and EGCG are not mediated through the ER.

Nuclear localization of $N F-\kappa B$ following combination treatment. One important downstream target of EGFR/AKT signaling is the nuclear factor- $\kappa \mathrm{B}(\mathrm{NF}-\kappa \mathrm{B})$ family of transcription factors. Importantly, NF- $\kappa \mathrm{B}$ is constitutively active in MDA-MB-231 cells $(18,19)$, and the basal-like subtype of breast cancer exhibits a high degree of NF- $\kappa \mathrm{B}$ activity $(7,8)$. Therefore, we investigated the nuclear localization of one of the major NF-kB subunits, p65. Following treatment with EGCG + raloxifene, p65 nuclear translocation was significantly decreased from all other treatments following 6,12 and $18 \mathrm{~h}$ 
A

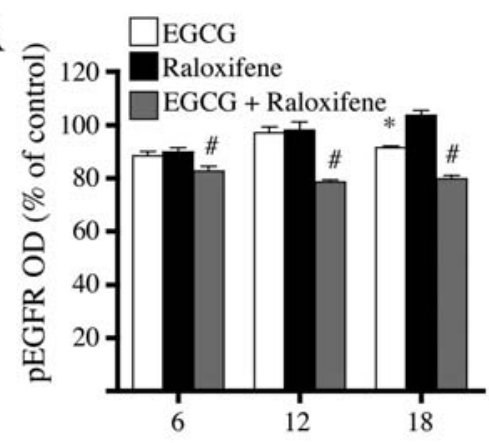

C

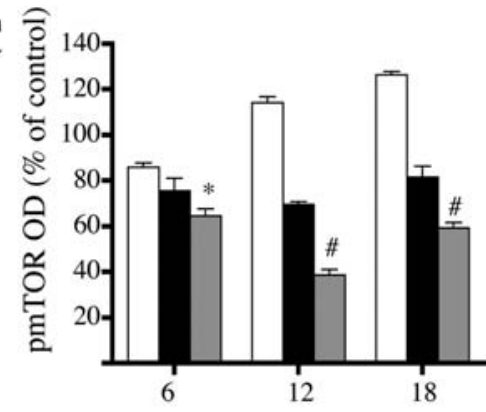

E

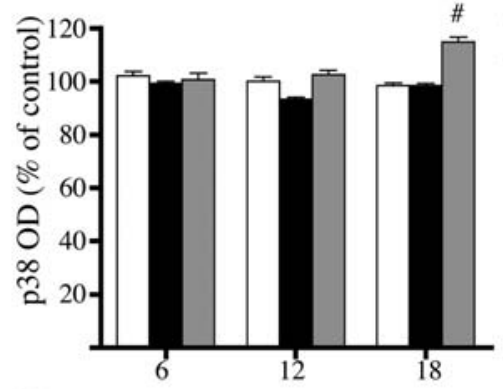

B
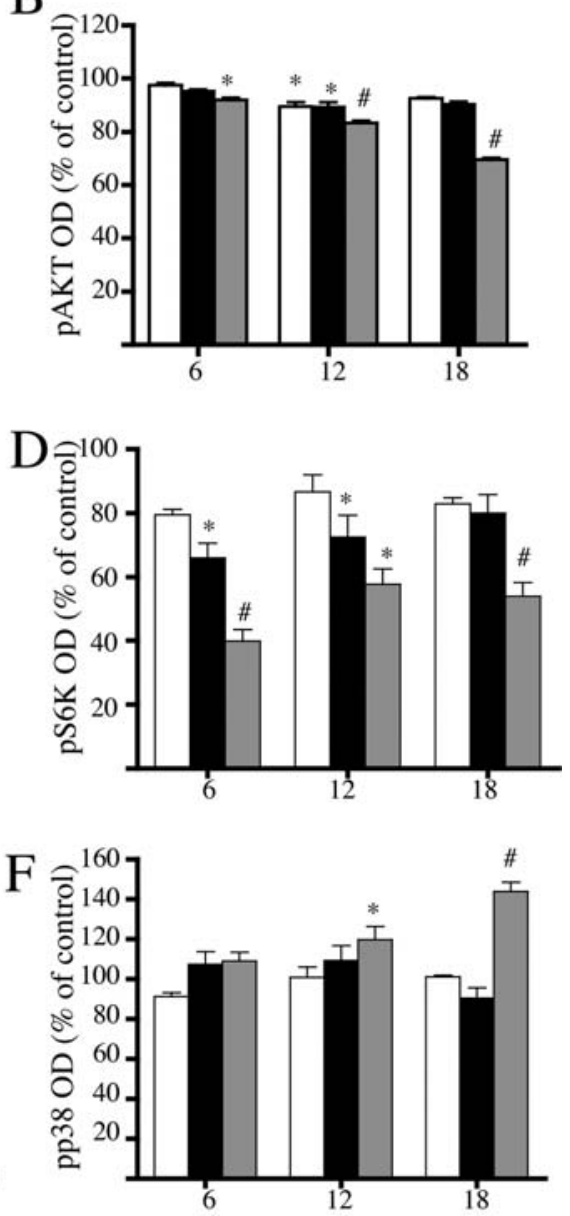

$\mathrm{H}$

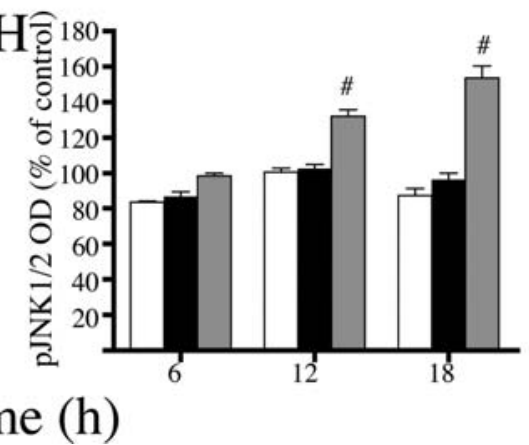

Figure 2. EGCG + raloxifene modulates the expression and phosphorylation of intracellular signaling proteins. Mean optical density of Western blots. Bars represent mean \pm SEM optical density of each treatment $(n=4)$. All bands were normalized to actin. For clarity only proteins from Fig. 1 that were significantly altered are graphed (A, pEGFR; B, pAKT; C, pmTOR; D, pS6K; E, p38; F, pp38; G, JNK1/2; H, pJNK1/2). Data were analyzed using a two-way ANOVA coupled with a Bonferroni post-hoc test where $\mathrm{p}<0.05$ was required for a statistically significant difference. ${ }^{*}$ Significantly different from control; "significantly different from all other treatments.

$(47.3 \pm 4.8 \%, 49.7 \pm 4.5 \%$ and $71.2 \pm 7.8 \%$ of control, respectively, $\mathrm{p}<0.05$ ) (Fig. 4A). This reduced nuclear localization of p65 was associated with an increase in its cytosolic expression $(137.8 \pm 7.2 \%, 132.6 \pm 8.2 \%$ and $127.6 \pm 8.9 \%$ of control, respectively, $\mathrm{p}<0.05)$ (Fig. 4B). As a positive control for p65 nuclear localization, MDA-MB-231 cells were serum starved for $24 \mathrm{~h}$ after which they were exposed to $10 \mathrm{ng} / \mathrm{ml}$ of TNF- $\alpha$. Following 5, 15 and $30 \mathrm{~min}$, nuclear expression of p65 was increased to $359.3 \%, 567.5 \%$ and $492.4 \%$ of control while the cytosolic expression of p65 was reduced to $81.8 \%$, $45.1 \%$ and $26.1 \%$ of the control (Fig. 4C).

\section{Discussion}

Previously we have reported that the combination of EGCG and raloxifene exhibits an enhanced cytotoxic response toward MDA-MB-231 breast cancer cells. We demonstrated that this cytotoxicity was elicited as a result of enhanced apoptosis induction, occurring independently of changes in cell cycle progression (16). We further investigated the mechanism of this effect via Western blotting of total protein expression and phosphorylation of EGFR and AKT proteins, where we observed a significant reduction in the 

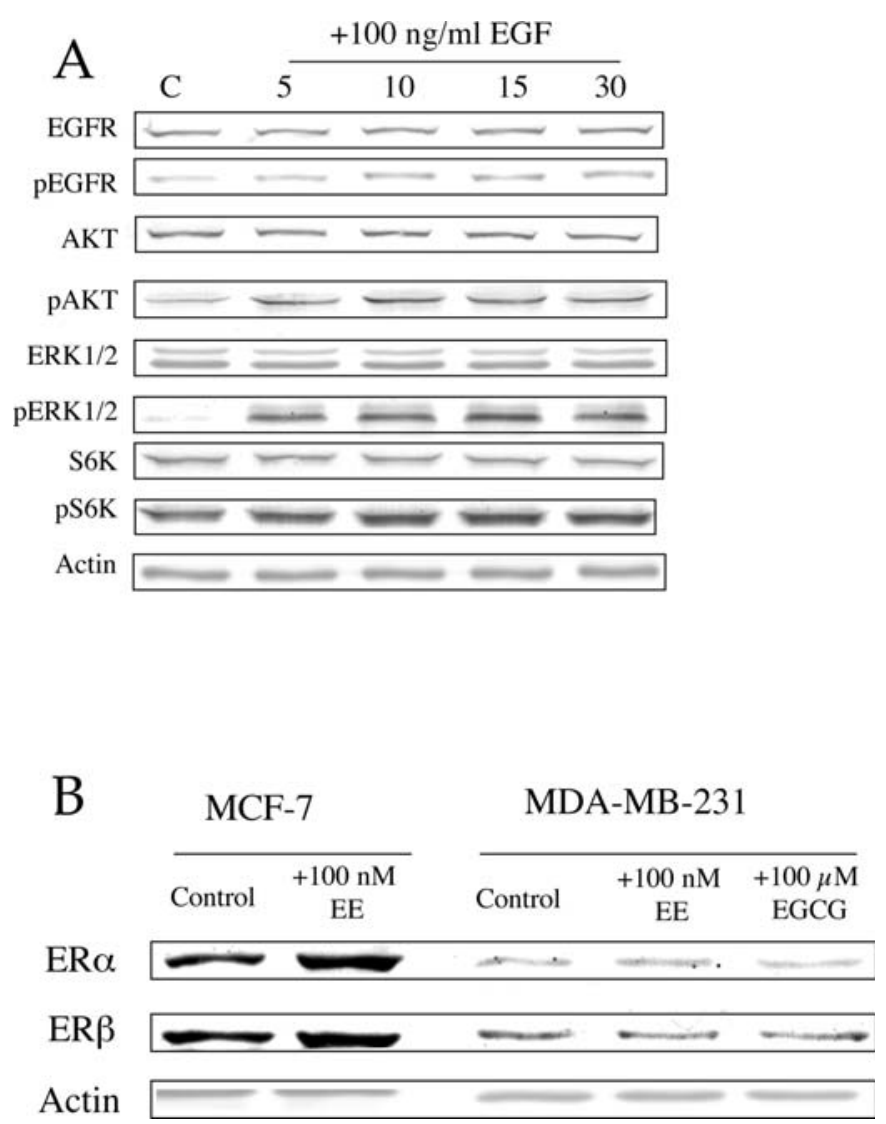

Figure 3. MDA-MB-231 cells lack ER $\alpha$ and ERß expression but have valid EGFR-mediated signaling. (A) MDA-MB-231 cells were serum-starved for $24 \mathrm{~h}$ prior to treatment with $100 \mathrm{ng} / \mathrm{ml}$ of EGF for $5,10,15$ or $30 \mathrm{~min}$. Representative Western blots of total protein expression and protein phosphorylation of EGFR, AKT, ERK1/2 and S6K. (B) MDA-MB-231 cells or MCF-7 cells were treated with $100 \mathrm{nM}$ of ethynlestradiol (EE) and/or $100 \mu \mathrm{M}$ of EGCG for $24 \mathrm{~h}$. The blots shown are representative of three independent experiments

phosphorylation of both proteins following $18 \mathrm{~h}$ (16). Therefore, the aim of the current investigation was to further probe the underlying mechanism of this combination treatment. In order to achieve this we investigated the effect of this treatment regime on the expression and phosphorylation of various proteins, important for cell survival and proliferation as well as the nuclear localization of p65, a major subunit of the NF- $\mathrm{B}$ transcription factor complex.

Results from the Western immunoblotting experiments revealed that the combination treatment reduced the phosphorylation of several proteins critical for MDA-MB-231 proliferation and survival. Specifically, we observed significant decreases in the phosphorylation of EGFR, AKT, mTOR and S6K following 6,12 and $18 \mathrm{~h}$. Complimentary to this observation, the phosphorylation of the SAPKs, JNK1/2 and p38, were increased following 12 and $18 \mathrm{~h}$. Excluding our previous publication, this is the only investigation into the therapeutic potential of this combination treatment in any tissue culture system. With regard to our previous results, the data correlate well with the time-course over which apoptosis induction is observed. Specifically, the greatest reductions in the phosphorylation of EGFR, AKT, S6K and mTOR are observed between 12 and $18 \mathrm{~h}$ (with the exception of S6K, where the greatest suppression of phosphorylation occurred after $6 \mathrm{~h}$ ) while the greatest increases in SAPK phosphorylation were observed after $18 \mathrm{~h}$. Our previous report demonstrated that apoptosis induction was significantly increased versus all other treatments following 12, 18, 24 and $36 \mathrm{~h}$ (16). Importantly, pharmacological inhibition of EGFR, AKT and mTOR in MDA-MB-231 human breast cancer cells all result in the induction of apoptosis. Furthermore, we have also demonstrated in vivo that the concomitant suppression of mTOR, Akt and EGFR results in a powerful tumor suppression (75\% smaller than control) in an MDAMB-231 xenograft model (20). With this in mind our in vitro data suggest that the combination of EGCG and raloxifene is also likely to elicit a strong tumor suppressive effect in this model.

While other groups have not previously investigated this combination treatment, EGCG has received considerable attention as a potential cancer therapeutic agent. EGCG has been investigated for its ability to modulate the expression and phosphorylation of intracellular signaling proteins in a number of in vitro models of cancer including bladder (21) breast (22), cervical (23), colon (24), and prostate (25). However, evidence for EGCG modulating protein expression or phosphorylation in the MDA-MB-231 cell line is limited. One study demonstrated that 50 and $80 \mu \mathrm{g} / \mathrm{ml}$ of EGCG treatment for $24 \mathrm{~h}$ (approximately $109 \mu \mathrm{M}$ and $174 \mu \mathrm{M}$, respectively) decreased the ratio of Ser473 phosphorylated AKT to total AKT by $25 \%$ and $90 \%$ of control, respectively, while no change was observed in the total expression of AKT in MDA-MB-231 cells (22). In another study, MDA-MB-231 cells were serum starved for $24 \mathrm{~h}$ and treated with $30 \mu \mathrm{g} / \mathrm{ml}$ of EGCG (approximately $65 \mu \mathrm{M}$ ) for a further $24 \mathrm{~h}$. The cells were then assessed for the total expression and phosphorylation of EGFR, AKT and ERK1/2, where EGCG appeared to only alter the phosphorylation of EGFR. However, MDA-MB-231 cells subjected to the same treatment, and stimulated with $50 \mathrm{ng} / \mathrm{ml}$ of TGF $3 \mathrm{~h}$ prior to harvesting, exhibited a marked reduction in EGFR and AKT phosphorylation and a modest reduction in ERK $1 / 2$ phosphorylation, while total EGFR, AKT or ERK1/2 expression was not altered (26). Therefore, our observation of reduced EGFR, AKT and ERK1/2 phosphorylation in MDA-MB-231 cells following EGCG treatment is supported by other groups.

As we observed changes in the phosphorylation status of EGFR, AKT, mTOR and S6K, we then sought to investigate how this treatment regime influenced the subcellular localization of p65, a major subunit of the NF- $\mathrm{BB}$ family of transcription factors. Importantly, constitutive NF- $\mathrm{KB}$ activity is often observed in ER-negative breast tumors (27), and is a defining characteristic of the basal-like breast cancer subtype $(7,8,25,27)$. Furthermore, constitutive NF-кB has been reported in the MDA-MB-231 cell line $(25,27-30)$. We observed that the nuclear localization of p65 was reduced after 6,12 , and $18 \mathrm{~h}$, where the combination treatment significantly reduced nuclear localization compared to both EGCG and raloxifene treatments. We further observed that raloxifene significantly reduced p65 nuclear localizations, however EGCG did not elicit any such effect. While raloxifene has been reported to reduce constitutive NF- $\mathrm{NB}$ activity in vitro, these studies have 
A

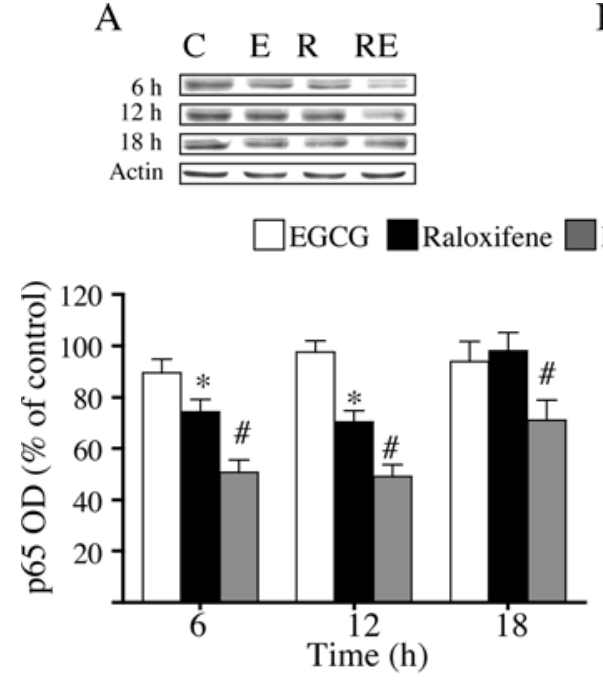

B

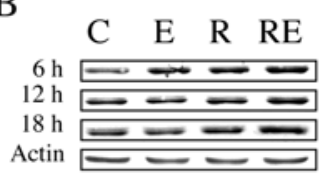

EGCG + Raloxifene

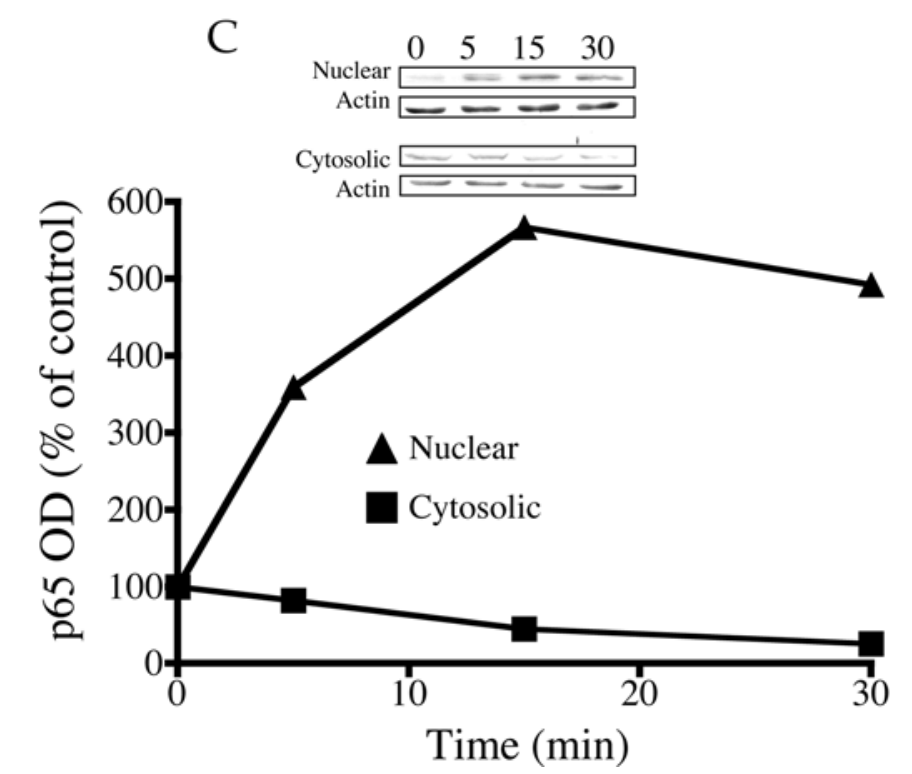

Figure 4. Effect of combination treatment on p65 subcellular localization. Cells were treated with either EGCG (25 $\mu \mathrm{M})$, raloxifene (4 $\mu \mathrm{M})$ or a combination of the two for 6, 12 or $18 \mathrm{~h}$. Nuclear and cytosolic extracts were prepared and subjected to Western immunoblotting. Representative Western blots of (A) Nuclear and (B) Cytosolic fractions. C, control; E, EGCG; R, raloxifene; RE, EGCG + raloxifene. Bars represent mean \pm SEM optical density of each treatment $(n=4)$. All bands were normalized to actin. Data were analyzed using a two-way ANOVA coupled with a Bonferroni post-hoc test where p $<0.05$ was required for a statistically significant difference. *Significantly different from control; " significantly different from all other treatments. (C) Cells were serum-starved for $24 \mathrm{~h}$ prior to treatment with $10 \mathrm{ng} / \mathrm{ml}$ of TNF- $\alpha$ for 5,15 or $30 \mathrm{~min}$. Nuclear and cytosolic fractions were prepared and subjected to Western immunoblotting. All bands were normalized to actin and the symbols represent the mean normalized optical density of each treatment ( $\mathrm{n}=4)$.

exclusively been carried out in ER-positive models (31-33). EGCG has also been reported to abrogate NF-кB activity in vitro, however these studies were carried out at concentrations of EGCG exceeding that, which was utilized in this investigation $(32,33)$ and thus concentrations as low as $25 \mu \mathrm{M}$ do not alter NF- $\mathrm{B}$ activity.

Previously, we have reported that the combination of EGCG and raloxifene is effective at inducing apoptosis in MDA-MB-231 cells (16). From the data presented in the current investigation, we have demonstrated that this combination treatment decreases the phosphorylation of three key signaling proteins, mTOR, Akt and EGFR, as well as induces the phosphorylation of the SAPKs, JNK1/2 and P38. Furthermore, these changes in protein phosphorylation were associated with reduced nuclear localization of p65. While EGCG has upregulated the expression of the ER in cell lines that display a low expression of the ER (34), it did not increase the expression of the ER in MDA-MB-231 cells. Therefore, we can conclude that the responses elicited following the combination of EGCG and raloxifene are produced independently of the ER. Overall, these results suggest that this combination treatment be further examined in in vivo models of ER-negative/Her-2 negative breast cancer.

\section{Acknowledgements}

Funding for this study was obtained from a grant from the Martine Elizabeth Breast Cancer Bequest (R.J.R.) and 
University of Otago Postgraduate Scholarships (E.C.S., R.M.J.).

\section{References}

1. Fisher E, Osborne C, McGuire W, et al: Correlation of primary breast cancer histopathology and estrogen receptor content. Breast Cancer Res Treat 1: 37-41, 1981.

2. Fisher E, Redmond C, Liu H, Rockette H and Fisher B: Correlation of estrogen receptor and pathologic characteristics of invasive breast cancer. Cancer 45: 349-353, 1980.

3. Osborne C: Steroid hormone receptors in breast cancer management. Breast Cancer Res Treat 51: 227-238, 1998.

4. Osborne C, Yochmowitz M, Knight III W and McGuire W: The value of estrogen and progesterone receptors in the treatment of breast cancer. Cancer 46: 2884-2888, 1980.

5. Bertucci F, Finetti P, Rougemont J, et al: Gene expression profiling identifies molecular subtypes of inflammatory breast cancer. Cancer Res 65: 2170-2178, 2005.

6. Kapp AV, Jeffrey SS, Langerød A, et al: Discovery and validation of breast cancer subtypes. BMC Genomics 7: 231, 2006.

7. Perou CM, Sorlie T, Eisen MB, et al: Molecular portraits of human breast tumours. Nature 406: 747-752, 2000.

8. Sorlie T, Perou CM, Tibshirani R, et al: Gene expression patterns of breast carcinomas distinguish tumor subclasses with clinical implications. Proc Natl Acad Sci USA 98: 10869-10874, 2001

9. Sotiriou C, Neo SY, McShane LM, et al: Breast cancer classification and prognosis based on gene expression profiles from a population-based study. Proc Natl Acad Sci USA 100: 10393-10398, 2003

10. Hudis CA: Trastuzumab-mechaism of action and use in clinical practice. N Engl J Med 357: 39-51, 2007.

11. MacGregor JI and Jordan VC: Basic guide to the mechanisms of antiestrogen action. Pharmacol Rev 50: 151-196, 1998.

12. Plosker GL and Keam SJ: Trastuzumab: A review of it use in the managment of Her-2 positive metastatic and early-stage breast cancer. Drugs 66: 449-475, 2006.

13. Slamon D, Leyland-Jones B, Shak S, et al: Use of chemotherapy plus a monoclonal antibody against HER2 for metastatic breast cancer that overexpresses HER2. N Engl J Med 344: 783-792, 2001

14. Vogel V, Costantino J, Wickerham D, et al: Effects of tamoxifen vs raloxifene on the risk of developing invasive breast cancer and other disease outcomes: the NSABP Study of Tamoxifen and Raloxifene (STAR) P-2 trial. JAMA 295: 2727-2741, 2006.

15. Cummings S, Eckert S, Krueger K, et al: Nickelsen T, Bjarnason NH, Morrow M, Lippman ME, Black D, et al. The effect of raloxifene on risk of breast cancer in postmenopausal women: results from the MORE randomized trial. Multiple outcomes of raloxifene evaluation. JAMA 281: 2189-2197, 1999

16. Stuart EC and Rosengren RJ: The combination of raloxifene and epigallocatechin gallate suppresses growth and induces apoptosis in MDA-MB-231 cells. Life Sci 82: 943-948, 2008.

17. Smith PK, Krohn RI, Hermanson GT, et al: Measurement of protein using bicinchoninic acid. Anal Biochem 150: 76-85, 1985.

18. Biswas D and Iglehart J: Linkage between EGFR family receptors and nuclear factor kappaB (NF-kappaB) signaling in breast cancer. J Cell Physiol 209: 645-652, 2006.

19. Nakshatri H and Goulet R Jr : NF-kappaB and breast cancer. Curr Probl Cancer 26: 282-309, 2002.
20. Scandlyn MJ, Stuart EC, Somers-Edgar TJ, Menzies AR and Rosengren RJ: A new role for tamoxifen in oestrogen receptor negative breast cancer when it is combined with epigallocatechin gallate. Br J Cancer 99: 1056-1063, 2008.

21. Qin J, Xie L, Zheng X, et al: A component of green tea, (-)epigallocatechin-3-gallate, promotes apoptosis in T24 human bladder cancer cells via modulation of the PI3K/Akt pathway and Bcl-2 family proteins. Biochem Biophys Res Commun 354: $852-857,2007$

22. Thangapazham R, Passi N and Maheshwari R: Green tea polyphenol and epigallocatechin gallate induce apoptosis and inhibit invasion in human breast cancer cells. Cancer Biol Ther 6: 1938-1943, 2007.

23. Sah J, Balasubramanian S, Eckert R and Rorke EA: Epigallocatechin-3-gallate inhibits epidermal growth factor receptor signaling pathway. Evidence for direct inhibition of ERK1/2 and AKT kinases. J Biol Chem 279: 12755-12762, 2004.

24. Shimizu M, Deguchi A, Lim J, Moriwaki H, Kopelovich L and Weinstein I: (-)-Epigallocatechin gallate and polyphenon $\mathrm{E}$ inhibit growth and activation of the epidermal growth factor receptor and human epidermal growth factor receptor-2 signaling pathways in human colon cancer cells. Clin Cancer Res 11: 2735-2746, 2005.

25. Siddiqui I, Adhami V, Afaq F, Ahmad N and Mukhtar H: Modulation of phosphatidylinositol-3-kinase/protein kinase Band mitogen-activated protein kinase-pathways by tea polyphenols in human prostate cancer cells. J Cell Biochem 91: 232-242, 2004

26. Masuda M, Suzui M, Lim J, Deguchi A, Soh J and Weinstein I: Epigallocatechin-3-gallate decreases VEGF production in head and neck and breast carcinoma cells by inhibiting EGFR-related pathways of signal transduction. J Exp Ther Oncol 2: 350-359, 2002.

27. Zhou YE, Marx C, Yau C, Scott GK, Eppenberger U and Benz CC: Activation of nuclear factor-kappaB (NFkappaB) identifies a high-risk subset of hormone-dependent breast cancers. Int J Biochem Cell Biol 37: 1130-1144, 2005.

28. Biswas DK, Cruz AP, Gansberger E and Perdee AB: Epidermal growth factor-induced nuclear factor kappaB activation: a major pathway of cell cycle progression in estrogen receptor negative breast cancer cells. Proc Natl Acad Sci USA 97: 8542-8547, 2000.

29. Vogelstein BK: Cancer genes and the pathways they control. Nat Med 10: 789-799, 2004

30. Yehiely F, Evans JR, Nielsen TO and Cryns VL: Deconstructing the molecular portrait of basal-like breast cancer. Trends Mol Med 12: 537-544, 2006

31. Kawagoe J, Takahashi T, Ohshima C, Mabuchi S, Takahashi K and Igarashi $\mathrm{H}$ : Raloxifene inhibits estrogen-induced up-regulation of telomerase activity in a human breast cancer cell line. J Biol Chem 278: 3363-3372, 2003.

32. Liu H, Gajdos C, Pearce ST, Chen B, Osipo C, Loweth J, McKian K, De Los Reyes A, Wing L and Jordan VC: Apoptotic action of 17beta-estradiol in raloxifene-resistant MCF-7 cells in vitro and in vivo. J Natl Cancer Inst 95: 1586-1597, 2003.

33. Olivier S, Castermans E, de Leval L, Tabruyn S, Chariot A and Malaise M: Raloxifene-induced myeloma cell apoptosis: a study of nuclear factor-kappaB inhibition and gene expression signature. Mol Pharmacol 69: 1615-1623, 2006.

34. Belguise K, Guo S and Sonenshein GE: Activation of FOXO3a by the green tea polyphenol epigallocatehin-3-gallate induces estrogen receptor a expression reversing invasive phenotype of breast cancer cells. Cancer Res 67: 5763-5770, 2007. 